\title{
COMPOSITIONAL AND GEOMETRICAL ISOMERS OF 15-METALLACROWN-5 COMPLEXES
}

\author{
DIMITRI P. KESSISSOGLOU, * JEFF KAMPF and VINCENT L. PECORARO $\dagger$
}

The Willard H. Dow Laboratory, Department of Chemistry, University of Michigan, Ann Arbor, MI 48109-1055, U.S.A.

(Received 1 April 1993; accepted 25 November 1993)

\begin{abstract}
Two mixed valent, hexanuclear manganese clusters of general composition $\mathrm{Mn}$ (acetate) ${ }_{2}\left[\mathrm{Mn}(\mathrm{III})(\text { salicylhydroximate) }]_{5} \text { (pyridine) }\right)_{6}, \mathrm{Mn}(\mathrm{II})(\mathrm{OAc})_{2}\left(15-\mathrm{MC}_{\mathrm{Mn}^{3+} \mathrm{N}}-5\right)$ have been prepared in $\approx 70 \%$ yield. Structural characterization of these complexes using $\mathrm{X}$-ray crystallography provides the first examples of 15 membered ring metallacrowns. A 15 membered chelate ring is constructed of five [Mn(III)- $\mathrm{N}-\mathrm{O}$ ] linkages. The five manganese(III) ions are designated $\mathrm{Mn}(1)-\mathrm{Mn}(5)$. The $\mathrm{Mn}(1), \mathrm{Mn}(2)$ and $\mathrm{Mn}(3)$ atoms adopt propeller configurations with $\Lambda, \Delta, \Lambda$ absolute stereochemistry, respectively. The $\mathrm{Mn}(4)$ and $\mathrm{Mn}(5)$ atoms are restricted to planar configurations. Both complexes contain a seven coordinate manganese(II) [Mn(6)] encapsulated in the core of this 15 membered ring. The $\mathrm{Mn}(6)$ polyhedron is best described using an 8 coordinate reference frame in which one of the vertices of a trigonal faced dodecahedron is vacant. The $\mathrm{Mn}(6)$ coordination sphere contains five hydroximate oxygen donors, provided by the metallacrown ring, and two oxygens from acetates that bridge between ring manganese(III) and the encapsulated manganese(II). Two geometrical isomers are formed that differ in the bridging acetate modes. In 1, the bridging acetate forms a bifurcated bridge between $\mathrm{Mn}(2)$ and $\mathrm{Mn}(6)$ while complex 2 has a bifurcated acetate bridge between $\mathrm{Mn}(5)$ and $\mathrm{Mn}(6)$. A compositional isomer, $\mathrm{Mn}(\mathrm{II})$ (acetate)(HSal)(15- $\left.\mathrm{MC}_{\mathrm{Mn}^{3+} \mathrm{N}^{-}}-5\right)$, 4, which substitutes the carboxylate function of salicylate for one of the acetates has also been prepared. This isomer adopts the same bifurcation mode, using the salicylate carboxylate, as complex 2 . Studies to define the solution integrity of the metallacrowns are presented in addition to the solid state structures.
\end{abstract}

The crown ethers are the paradigm of the molecular class of polyether metal sequestration agents. ${ }^{1,2}$ These neutral, cyclic molecules form metal binding cavities composed of ether oxygen atoms. Specificity for alkali metal and alkaline earth cations can be achieved by adding methylene spacers or additional oxygen atoms that increase the cavity size and potential denticity of the ligand. ${ }^{3}$ To a first approximation these compounds are often considered to show selectivity based on a match

\footnotetext{
* On sabbatical leave from the Department of General and Inorganic Chemistry, Aristotle University of Thessaloniki, 54006 Thessaloniki, Greece.

$\dagger$ Author to whom correspondence should be addressed.
}

between the ligand cavity size and the ionic radius of the cation to be encapsulated, ${ }^{4}$ although $\mathrm{Gokel}^{5}$ has shown that selectivity follows metal ion hydration energy regardless of ring size. Crown ether complexes of transition metal ions are rare, presumably because the donor capacity of a neutral oxygen atom to a transition metal ion is poor. For this reason, variants of crown molecules containing other heteroatoms have been prepared. ${ }^{4,6-9}$ The metal complexes of these ligands exhibit interesting properties [e.g. the stabilization of low spin cobalt (II)] and altered preferences for transition metal ions. Although analogues that substitute sulphur (crown thiaethers ${ }^{7}$ ) or nitrogen (cyclams ${ }^{9}$ ) for the ring oxygen atoms are well known, comparable systems that substitute heteroatoms for the ring car- 
bons (the metallacrown analogy ${ }^{10}$ ) have not been explored to any extent. Lehn ${ }^{6}$ has demonstrated how organic structures can be prepared using crown ether or cyclam based ligands to provide supramolecular architectures that lead to selective recognition of neutral organics, cations, anions or simultaneous combinations of these three substrate types. Exploitation of the metallacrown analogy, while keeping in mind the utility of the supramolecule concept, could lead to a strategy that may prove highly successful for the controlled preparation of moderate nuclearity (3-12 metal atom), mixed metal and mixed valent clusters with predesigned molecular frameworks.

Metallacrowns ${ }^{10}$ are formed by linking transition and main group metal ions into cyclic ensembles using two heteroatom bridging atoms such as $\mathrm{N}$ and $O$. These assemblies result in neutral cores that have metal binding cavities that are similar in size and shape to organic crown ethers. The majority of metallacrowns have been prepared using salicylhydroxamic acid $\left(\mathrm{H}_{3} \mathrm{SHI}\right)$, shown in Scheme 1 , as the ligand that provides the nitrogen and oxygen donors to the metallacrown ring metals; however, a recent report of copper(II)[Cu(II)( $\beta$-alaninehydroxamic acid] $]_{4}$ has appeared. ${ }^{\text {Th }}$ The triply deprotonated form of SHI, illustrating the four potential metal binding sites, is shown as B. One metal can bind in a five-membered chelate ring formed through the hydroximate group while a second metal can bind to the 6-membered substituted iminophenolate ring. This yields metal clusters with $\mathrm{M}-\mathrm{N}-\mathrm{O}-\mathrm{M}$ networks linking the ring metals (Form C). Stoichiometries of $[\mathrm{M}(\mathrm{SHI})]_{n}$ where $n=3$ and 4 lead to the 9-metallacrown-3 (9-MC3) and 12-metallacrown-4 (12-MC-4) ring systems illustrated as Fig. 1. X-ray structural characterization of numerous 9-MC- $3^{12,13}$ and 12-MC$4^{10,14,15}$ complexes demonstrated that the cavity sizes of metallacrowns are essentially identical to the corresponding crown ethers and that various ions can be incorporated into the central cavity. Both 15MC-5 and 18-MC-6 structures are important synthetic targets since these molecules would both extend the generality of the metallacrown analogy and allow for the preparation of higher nuclearity

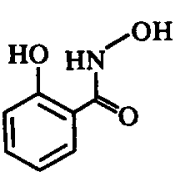

A
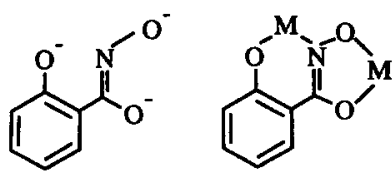

C
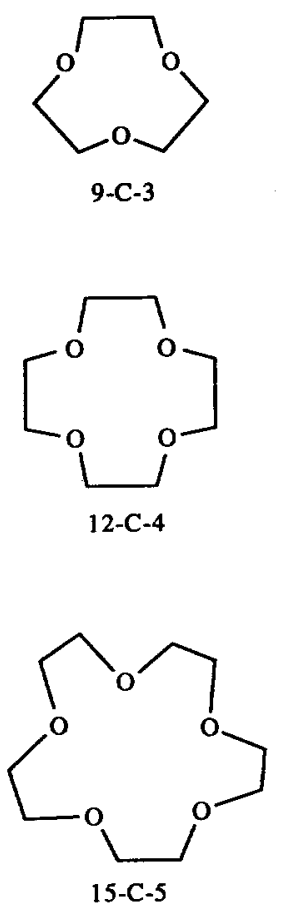

Crown and metallocrown analogy

Fig. 1. A representation of the crown ether/metallacrown analogy. The SHI ligands are omitted from the 12-MC-4 and 15-MC-5 structures for clarity.

clusters. Herein we demonstrate, by presenting the $\mathrm{X}$-ray structures of two mixed valent, hexanuclear manganese clusters of the form [Mn(acetate) ${ }_{2}$ $[\mathrm{Mn} \text { (III)(salicylhydroximate) }]_{5}$ (pyridine) $\left.{ }_{6}\right]$, that 15-MC-5 structures can be achieved by altering the stereochemistry around the ring metal ions and discuss the types of isomerism available to these 15-

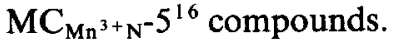

\section{EXPERIMENTAL}

\section{Materials}

Salicylhydroxamic acid was obtained from Aldrich Chemical Co. $\mathrm{Mn}\left(\mathrm{CH}_{3} \mathrm{COO}\right)_{3} \cdot 2 \mathrm{H}_{2} \mathrm{O}$ and $\mathrm{Mn}\left(\mathrm{CH}_{3} \mathrm{COO}\right)_{2} \cdot 2 \mathrm{H}_{2} \mathrm{O}$ were obtained from Fluka Co. Tetra-n-butylammonium hexafluorophosphate $\left[\mathrm{TBAPF}_{6}\right.$ ] was synthesized by the metathesis of $\mathrm{TBABr}$ and $\mathrm{NH}_{4} \mathrm{PF}_{6}$ in water followed by three recrystallizations from absolute ethanol. For the electrochemical studies, high purity solvents (methylene chloride, dimethyl formamide [DMF] and methanol) were used as received from American Burdick and Jackson Co. High purity argon gas was used to deoxygenate solutions. All other chemicals and solvents were reagent grade. 


\section{Preparation of compounds}

$\operatorname{Mn}(\text { acetate })_{2}[\mathrm{Mn}(\mathrm{III})$ (salicylhydroximate $\left.)\right]_{5}$ (pyridine $)_{6} 1$ and $\mathrm{Mn}\left(\right.$ acetate) ${ }_{2}[\mathrm{Mn}(\mathrm{III})$ (salicylhydroxi-

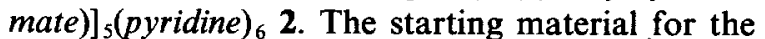
synthesis, $\mathrm{Mn}(\mathrm{II})(\mathrm{OAc})_{2}\left[\mathrm{Mn}(\mathrm{III})(\mathrm{SHI})(\mathrm{DMF})_{1.5}\right]_{4}$, 3 , was prepared as described previously ${ }^{10,14}$ and was dissolved $(0.10 \mathrm{mmol})$ in $50 \mathrm{~cm}^{3}$ of methanol. Pyridine $\left(2.5 \mathrm{~cm}^{3}\right)$ was added to this solution and the reaction mixture filtered. A black, crystalline product was obtained after slow evaporation $(\approx 12 \mathrm{~h})$. The crystals were blocks which subsequently were shown to belong to the triclinic crystal system $P \bar{I}$. After crystals of 1 were recovered, a second crop of black crystals deposited from the mother liquor $(\approx 4$ days). These rectangular prismatic crystals, 2 , belonged to the monoclinic space group $P 2_{1} / n$ and were used in subsequent $\mathrm{X}$-ray analysis. Both compounds exhibited the stoichiometry:

$\mathrm{Mn}(\mathrm{II})\left(\text { acetate) }{ }_{2}[\mathrm{Mn}(\mathrm{SHI}) \text { (pyrdine) })_{1.2}\right]_{5}$

$$
\text { - } \mathrm{CH}_{3} \mathrm{OH},\left\{\mathrm{Mn}(\mathrm{OAc})_{2}\left[15-\mathrm{MC}_{\mathrm{Mn}^{3+} \mathrm{N}^{-}} 5\right]\right\} \text {. }
$$

Found: $\mathrm{C} ; 49.9 ; \mathrm{H} ; 3.6 ; \mathrm{N}, 9.3 ; \mathrm{Mn}, 18.8$. Calc. for $\mathrm{Mn}_{6} \mathrm{C}_{70} \mathrm{H}_{60} \mathrm{~N}_{11} \mathrm{O}_{20}: \mathrm{C}, 49.3 ; \mathrm{H}, 3.5 ; \mathrm{N}, 9.0$; Mn, $19.3 \%$.

$\mathrm{Mn}($ acetate $)($ Hsalicylate) $[\mathrm{Mn}$ (III)(salicylhydroximate $]_{5}(\text { pyridine })_{6}, 4$. A third material 4 , formed black, crystalline product in very low yield $(5 \%)$ when the solution used above was allowed to evaporate for an additional week. These crystals were blocks which subsequently were shown to belong to the triclinic crystal system ${ }^{17} P \bar{I}$. Found : $\mathrm{C}, 49.9 ; \mathrm{H}, 3.2 ; \mathrm{N}, 8.3 ; \mathrm{Mn}, 18.2$. Calc. for $\mathrm{Mn}_{6} \mathrm{C}_{76} \mathrm{H}_{66} \mathrm{~N}_{11} \mathrm{O}_{22}: \mathrm{C}, 50.3 ; \mathrm{H}, 3.6 ; \mathrm{N}, 8.5 ; \mathrm{Mn}$, $18.2 \%$.

Spectroscopic, electrochemical and magnetic studies. ${ }^{1} \mathrm{H}$ NMR spectra of the complexes were obtained on a Bruker $360 \mathrm{MHz}$ FT-NMR spectrometer operating in the quadrature detection mode $\left({ }^{1} \mathrm{H}\right.$ frequency, $\left.360.1 \mathrm{MHz}\right)$. Spectra were collected by using a one pulse sequence with a $90^{\circ}$ pulse of $9.9 \mu$ s. Between 3000 and 10,000 transients were accumulated over a $50 \mathrm{kHz}$ bandwidth for each sample. The spectra contained $8 \mathrm{~K}$ data points, and the signal to noise ratio was improved by apodization of the free induction decay, which introduced a negligible $10-20 \mathrm{~Hz}$ line broadening. Chemical shifts were referenced to TMS or resonances due to residual protons present in the deuterated solvents.

UV-visible spectra were recorded on a PerkinElmer Lambda $9 \mathrm{UV} /$ vis/near-IR spectrophotometer equipped with a Perkin-Elmer 3600 data station. Infrared spectra were obtained on a
Nicolet $60-\mathrm{SX}$ FT-IR as $\mathrm{KBr}$ pellets. Solid state magnetic susceptibilities were determined using a Johnson-Matthey magnetic susceptibility balance [MSB-1], using $\mathrm{Hg}\left[\mathrm{Co}(\mathrm{SCN})_{4}\right]$ as a calibration standard. Solution magnetic susceptibilities were determined by using the Evans methods ${ }^{18,19}$ with a 360 $\mathrm{MHz}$ Bruker FT-NMR spectrometer. Magnetic moments from both methods are reported on a per manganese basis unless otherwise specified. Chemical analyses were performed at the Chemical Analysis Laboratory at the University of Michigan, Ann Arbor, MI.

Cyclic voltammetry was completed on a Bioanalytical Systems BAS-100 Electrochemical Analyzer. Cyclic voltammograms were generated using platinum bead, platinum wire and saturated calomel [SCE, within a Luggin probe] electrodes as the working, auxiliary and reference electrodes, respectively, in a three electrode configuration. Tetrabutylammonium hexafluorophosphate $\left[\mathrm{TBAPF}_{6}\right]$ was used as the supporting electrolyte at $0.1 \mathrm{M}$ concentration.

Collection and reduction of $X$-ray data. Single crystals of 1 and 2 were grown from methanol/ pyridine. Each crystal was then mounted in a glass capillary and data collected on a Syntex $P 2{ }_{1} / \mathrm{mv}$ or Siemens R $3 \mathrm{~m} / \mathrm{v}$ diffractometer. Intensity data were obtained using Mo- $K_{\alpha}$ radiation $(0.7107$ $\AA ̊$ ) monochromatized using a graphite crystal whose diffraction vector was parallel to the diffraction vector of the sample. Three standard reflections were measured every 97 reflections. Lattice parameters were determined from a least-squares refinement of reflection settings obtained from an automatic centering routine ( 20 for 1 and 25 for 2). Table 1 contains a summary of data collection conditions for 1 and 2. The data reduction, structure solution and refinement utilized the SHELXTL PLUS program package ${ }^{20}$ In the subsequent refinement, the function $\Sigma w\left(\left|F_{\mathrm{o}}\right|-\left|F_{\mathrm{c}}\right|\right)^{2}$ was minimized where $\left|F_{\mathrm{o}}\right|$ and $\left|F_{\mathrm{c}}\right|$ are the observed and calculated structure factor amplitudes. The agreement indices $R=$ $\Sigma|| F_{\mathrm{o}}|-| F_{\mathrm{c}}|/| F_{\mathrm{o}} \mid$ and $R_{\mathrm{w}}=\left[\Sigma\left(\left|F_{\mathrm{o}}\right|-\mid F_{\mathrm{c}}\right)^{2} / \Sigma \mathrm{w}\left|F_{\mathrm{o}}\right|^{2}\right]^{1 / 2}$ were used to evaluate the results. Atomic scattering factors are from The International Tables for X-Ray Crystallography. ${ }^{21}$ Hydrogen atoms were located, but not refined, and placed at fixed distances from bonded carbon atoms of $0.96 \AA$ in the final least-squares refinement. All hydrogen atoms were given a common isotropic thermal parameter which was allowed to refine as a free variable. Unique data and final $R$ indices for all structures are reported in Table 1 . Table 2 lists selected bond distances for these compounds. A complete crystallographic summary is found in Table S3. Fractional atomic coordinates for 
Table 1. Summary of crystallographic data for $\mathbf{1}$ and $\mathbf{2}$

\begin{tabular}{|c|c|c|}
\hline Compound & 1 & 2 \\
\hline Formula & $\mathrm{Mn}_{6} \mathrm{C}_{70} \mathrm{H}_{60} \mathrm{~N}_{1}, \mathrm{O}_{20}$ & $\mathrm{Mn}_{6} \mathrm{C}_{70} \mathrm{H}_{60} \mathrm{~N}_{11} \mathrm{O}_{20}$ \\
\hline Mol wt & 1705 & 1705 \\
\hline$a(\AA)$ & $12.842(3)$ & $14.188(3)$ \\
\hline$b(\AA)$ & $15.515(5)$ & $29.312(7)$ \\
\hline$c(\AA)$ & $18.365(7)$ & $17.226(4)$ \\
\hline$\alpha\left({ }^{\circ}\right)$ & $90.20(3)$ & 90 \\
\hline$\beta\left(^{\circ}\right)$ & $97.57(2)$ & $98.20(2)$ \\
\hline$\gamma\left({ }^{\circ}\right)$ & $102.71(2)$ & 90 \\
\hline$V\left(\AA^{3}\right)$ & $3536(2)$ & $7090(3)$ \\
\hline Cryst. syst. & triclinic & monoclinic \\
\hline Space group & $P \overline{\mathrm{I}}$ & $P 2_{1} / \mathrm{n}$ \\
\hline$D_{\text {calc }}\left(\mathrm{g} \mathrm{cm}^{-3}\right)$ & 1.60 & 1.60 \\
\hline$D_{\mathrm{obs}}\left(\mathrm{g} \mathrm{cm}^{-3}\right)$ & $1.62(1)$ & $1.59(1)$ \\
\hline$Z$ & 2 & 4 \\
\hline Radiation & $\begin{array}{l}\text { Mo- } K_{a} \\
(0.7107 \AA)\end{array}$ & $\begin{array}{l}\text { Mo- } K_{z} \\
(0.7107 \AA)\end{array}$ \\
\hline Abs. coeff. $(\mu)$ & $10.81 \mathrm{~cm}^{-1}$ & $10.82 \mathrm{~cm}^{-1}$ \\
\hline Temp. & $23^{\circ} \mathrm{C}$ & $-130^{\circ} \mathrm{C}$ \\
\hline Cryst. size (mm) & $0.24 \times 0.22 \times 0.32$ & $0.29 \times 0.18 \times 0.31$ \\
\hline Scan speed (degree $\min ^{-1}$ ) & $1.5-5.0$ & $1.5-5.0$ \\
\hline Scan range $\left(^{\circ}\right)$ & $5<2 \theta<45$ & $5<2 \theta<45$ \\
\hline Unique data & 8127 & 9125 \\
\hline \multirow[t]{2}{*}{ No. of obs. data } & 7043 & 6878 \\
\hline & $\left(F_{\mathrm{o}}\right)>0.6 \sigma(F)$ & $\left(F_{\mathrm{o}}\right)>4 \sigma(F)$ \\
\hline $\begin{array}{l}R \\
R_{w}\end{array}$ & 0.082 & 0.104 \\
\hline $\begin{array}{l}R_{\mathrm{w}} \\
\text { GOF }\end{array}$ & 0.029 & 0.065 \\
\hline GOF & 3.14 & 6.1 \\
\hline $\begin{array}{l}R=R=\Sigma|| F_{\mathrm{o}}|-| F_{\mathrm{c}}|/| F_{\mathrm{o}} \mid \\
R_{\mathrm{w}}=\left[\Sigma \mathrm{w}\left(\left|F_{\mathrm{o}}\right|-\mid F_{\mathrm{c}}\right)^{2} / \Sigma \mathrm{w} \mid F_{\mathrm{o}}\right.\end{array}$ & & \\
\hline
\end{tabular}

all non-hydrogen atoms of 1 and 2 are given in Tables S4 and S5 respectively. Figure 2 presents an ORTEP diagram of the entire molecule of 1 while Fig. 3 shows an ORTEP stereodiagram of the core of 1 . The coordination spheres of each of the ring manganese ions are illustrated in Fig. 4. The face capped octahedron of the manganese(II) ion in 1 is illustrated in Figs 5 and 6 while Fig. 7 shows a series of ORTEP diagrams that conceptually explain how 1 assembled the face capped octahedron of the manganese(II) ion in 1.

\section{RESULTS}

An ORTEP diagram of 1 is shown as Fig. 2 and an ORTEP stereodiagram of the $\mathrm{Mn}(\mathrm{OAc})_{2}(15-$ MC-5) core is presented as Fig. 3. Important bond distances are presented in Table 2. This neutral, hexanuclear cluster contains five manganese(III) ions $[\mathrm{Mn}(1)-\mathrm{Mn}(5)]$ that form the metallacrown ring. The $[\mathrm{Mn}-\mathrm{N}-\mathrm{O}]_{5}$ connectivity is emphasized by bold bonds in both Figs 2 and 3 . The specific connectivity of atoms to form the ring is : $\mathrm{Mn}(1)$
$\mathrm{N}(1)-\mathrm{O}(3)-\mathrm{Mn}(2)-\mathrm{N}(2)-\mathrm{O}(6)-\mathrm{Mn}(3)-\mathrm{N}(3)-$ $\mathrm{O}(9)-\mathrm{Mn}(4)-\mathrm{N}(4)-\mathrm{O}(12)-\mathrm{Mn}(5)-\mathrm{N}(5)-\mathrm{O}(15)$. A sixth manganese ion, $\mathrm{Mn}(6)$, is encapsulated into the $15-\mathrm{MC}-5$ cavity and is bound by five metallacrown ring oxygens $[O(3), O(6), O(9), O(12)$ and $O(15)]$ and two carboxylate oxygens $[O(16)$ and $O(19)]$. The encapsulated metal ion is a manganese(II) since there are: five SHI trianionic ligands, five-ring manganese(III) ions and two carboxylate ligands. The manganese(III) oxidation level for the ring manganese is supported by redox titration, analogous structural parameters to previously described manganese(III) metallacrowns, the room temperature magnetic properties and the sharp paramagnetically shifted proton NMR resonances (vide infra).

The first coordination spheres of the five ring manganese ions are illustrated in Fig. 4. Four coordination sites of these manganese ions are filled by the heteroatoms from two SHI ligands. The remaining sites are filled with nitrogen or oxygen atoms of pyridine or acetate, respectively. Using the two coordinated SHI residues for reference as 
Table 2. Selected average bond lengths for 1 and 2

\begin{tabular}{|c|c|c|c|}
\hline & & $\mathbf{1}$ & 2 \\
\hline \multicolumn{4}{|c|}{ Averages for propellar $\mathrm{Mn}(1-3)$} \\
\hline phenolate & $\mathrm{Mn}-\mathrm{O}(1,4,7)^{a}$ & $1.84(1)$ & $1.85(1)$ \\
\hline carbonyl & $\mathrm{Mn}-\mathrm{O}(14,11,8)$ & $2.14(4)$ & $2.15(3)$ \\
\hline hydroximate & $\mathrm{Mn}-\mathrm{O}(15,12,9)$ & $1.90(2)$ & $1.90(3)$ \\
\hline hydroximate & $M n-N(1,4,5)$ & $1.99(4)$ & $1.98(2)$ \\
\hline carboxylate & $\mathrm{Mn}-\mathrm{O}(16,18,17)$ & $2.26(15)$ & $2.31(14)$ \\
\hline pyridine & $M n-N(6,7,8)$ & $2.12(1)$ & $2.12(2)$ \\
\hline \multicolumn{4}{|c|}{ Averages for planar $\operatorname{Mn}(4,5)$} \\
\hline phenolate & $\mathrm{Mn}-\mathrm{O}(10,13)^{b}$ & $1.85(2)$ & $1.87(2)$ \\
\hline carbonyl & $\mathrm{Mn}-\mathrm{O}(8,11)$ & $1.94(1)$ & $1.96(4)$ \\
\hline hydroximate & $\mathrm{Mn}-\mathrm{O}(9,12)$ & $1.92(2)$ & $1.90(2)$ \\
\hline hydroximate & $\mathrm{Mn}-\mathrm{N}(4.5)$ & $1.94(1)$ & $1.96(1)$ \\
\hline carboxylate & $\mathrm{Mn}-\mathrm{O}(19)$ & $2.555(5)$ & $2.529(8)$ \\
\hline pyridine & $M n-N(6,10,11)$ & $2.37(5)$ & $2.30(2)$ \\
\hline \multicolumn{4}{|c|}{ Encapsulated $\mathrm{Mn}(6)$} \\
\hline & $\mathrm{Mn}-\mathrm{O}(3)$ & $2.282(4)$ & $2.220(8)$ \\
\hline & $\mathrm{Mn}-\mathrm{O}(6)$ & $2.211(4)$ & $2.188(8)$ \\
\hline & $\mathrm{Mn}-\mathrm{O}(9)$ & $2.253(4)$ & $2.156(8)$ \\
\hline & $\mathrm{Mn}-\mathrm{O}(12)$ & $2.398(4)$ & $2.213(8)$ \\
\hline & $\mathrm{Mn}-\mathrm{O}(15)$ & $2.206(4)$ & $2.198(7)$ \\
\hline & $\mathrm{Mn}-\mathrm{O}(16)$ & $2.275(4)$ & $2.374(8)$ \\
\hline & $\mathrm{Mn}-\mathrm{O}(19,18)^{c}$ & $2.171(4)$ & $2.261(8)$ \\
\hline
\end{tabular}

${ }^{a}$ Numbers in parentheses are arranged in the order of $\mathrm{Mn}(1)$ to $\mathrm{Mn}(3)$. Thus, these structures are the average of $\mathrm{Mn}(1)-\mathrm{O}(1)$; $\mathrm{Mn}(2)-\mathrm{O}(4), \mathrm{Mn}(3)-\mathrm{O}(7)$.

${ }^{b}$ Numbers in parentheses are arranged in the order $\operatorname{Mn}(4), \operatorname{Mn}(5)$. Thus, these distances are the average of $\mathrm{Mn}(4)-\mathrm{O}(10)$ and $\mathrm{Mn}(5)-\mathrm{O}(13)$.

${ }^{c} \mathrm{O}(19)$ is bound to $\mathrm{Mn}(6)$ in 1 and $\mathrm{O}(18)$ is bound to $\mathrm{Mn}(6)$ in 2.

shown in Scheme 2, three manganese(III) ions [Mn(1)-Mn(3)] adopt a propeller configuration (top of Fig. 4) while the remaining two [Mn(4) and $\mathrm{Mn}(5)]$ form planar structures (bottom of Fig. 4). Two of the metals in the propeller configuration $[\mathrm{Mn}(1)$ and $\mathrm{Mn}(3)]$ adopt the $\Delta$ absolute stereochemical configuration with the third [Mn(2)] constrained to the $\Lambda$ configuration. For the propeller manganese, the bound pyridine is always trans to the hydroximate nitrogen of SHI and the coordinated acetate is always trans to the carbonyl oxygen of SHI. The coordination spheres for $\mathrm{Mn}(4)$ and $\mathrm{Mn}(5)$ are as expected for manganese(III), with four short and two long distances; however, the propeller Mn ions do not show the typical JahnTeller axial elongation. Instead, there are three long and three short distances suggesting that this is a relatively less stable conformation than usually observed for manganese(III) ions. In all cases, the average bond distances for the ring metals

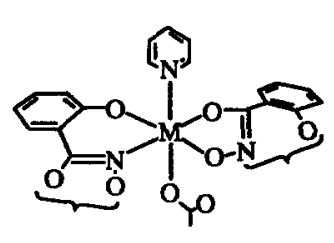

Planar

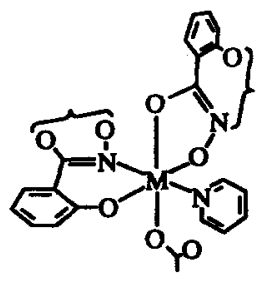

$\boldsymbol{\Lambda}$ Propeller

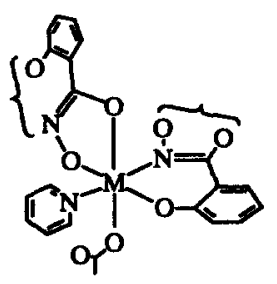

$\Delta$

Scheme 2. 


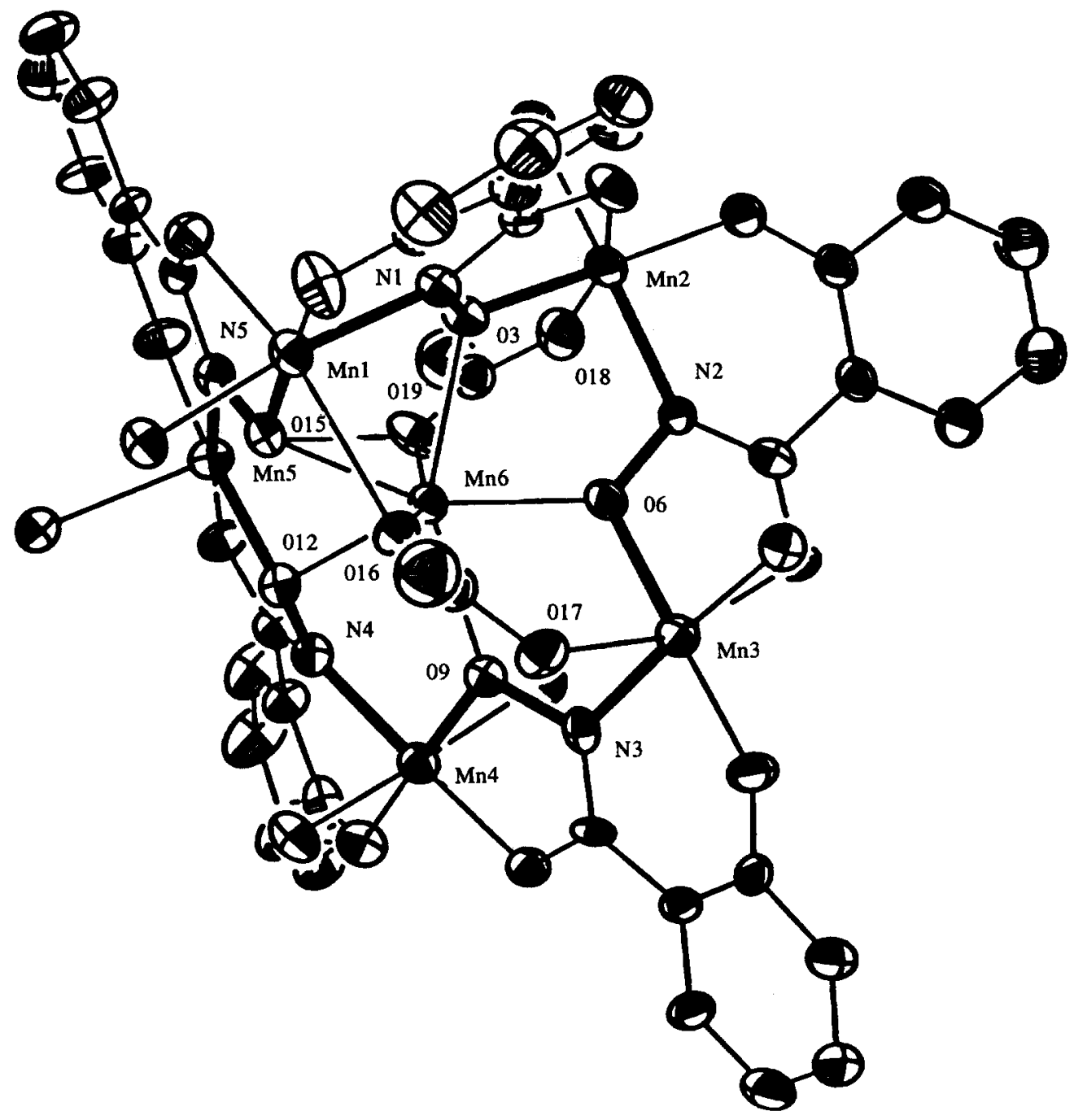

Fig. 2. An ORTEP diagram of complex 1. The metallacrown ring structure is highlighted with bold bonds. Pyridine rings were omitted for clarity.

are significantly shorter than the encapsulated manganese(II).

The encapsulated manganese(II) [Mn(6)], shown in Fig. 5, is seven coordinate with five donors from

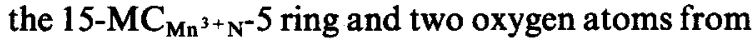
bridging acetate groups. As is illustrated in Fig. 6, the polyhedron of $\mathrm{Mn}(6)$ is best described using an 8 -coordinate reference frame in which one of the vertices is vacant. ${ }^{22} \mathrm{~A}$ trigonal faced dodecahedron has eight atom sites designated as $\mathrm{A}$ and $\mathrm{B}$ based on the position within the two trapezoids that define the structure (bold lines in the top drawing of Fig. 5). There are 18 edges, designated a (two, edge connecting $\mathrm{A}$ atoms within a trapezoid), b (four, connecting $B$ atoms between trapezoids), $m$ (four, connecting $A$ and $B$ atoms within trapezoids) and g (eight, connecting A and B atoms between trapezoids). A vacancy can occur either at the A site or the B site leading to distinct geometrical forms (an A vacancy leaves 10 faces, $1 \mathrm{a}, 4 \mathrm{~b}, 3 \mathrm{~m}$ and $6 \mathrm{~g}$ edges and define a new intratrapezoid $B-B$ edge while a B vacancy leaves 9 faces, 2 a, 2 b, $3 \mathrm{~m}$ and $6 \mathrm{~g}$ edges and again defines a new intratrapezoid B$B$ edge). The $M n(6)$ polyhedron best resembles the $B$ vacancy condition that is shown at the bottom of Fig. 6. The large dark sphere is $\operatorname{Mn}(6)$, the five smaller shaded spheres are the metallacrown ring oxygen atoms and the open spheres represent the carboxylate oxygen atoms. Beginning at $O(3)$ and ascending to $O(15)$, the metallacrown ring occupies edge positions $\mathbf{m}, \mathbf{a}, \mathbf{m}, \mathbf{g}$ and $\mathbf{g}$. Figure 7 conceptually illustrates the vacant metallacrown ring, insertion of the encapsulated manganese(II) and association of the bridging acetate to yield the final metallacrown, respectively.

The mixture of planar and propeller con- 


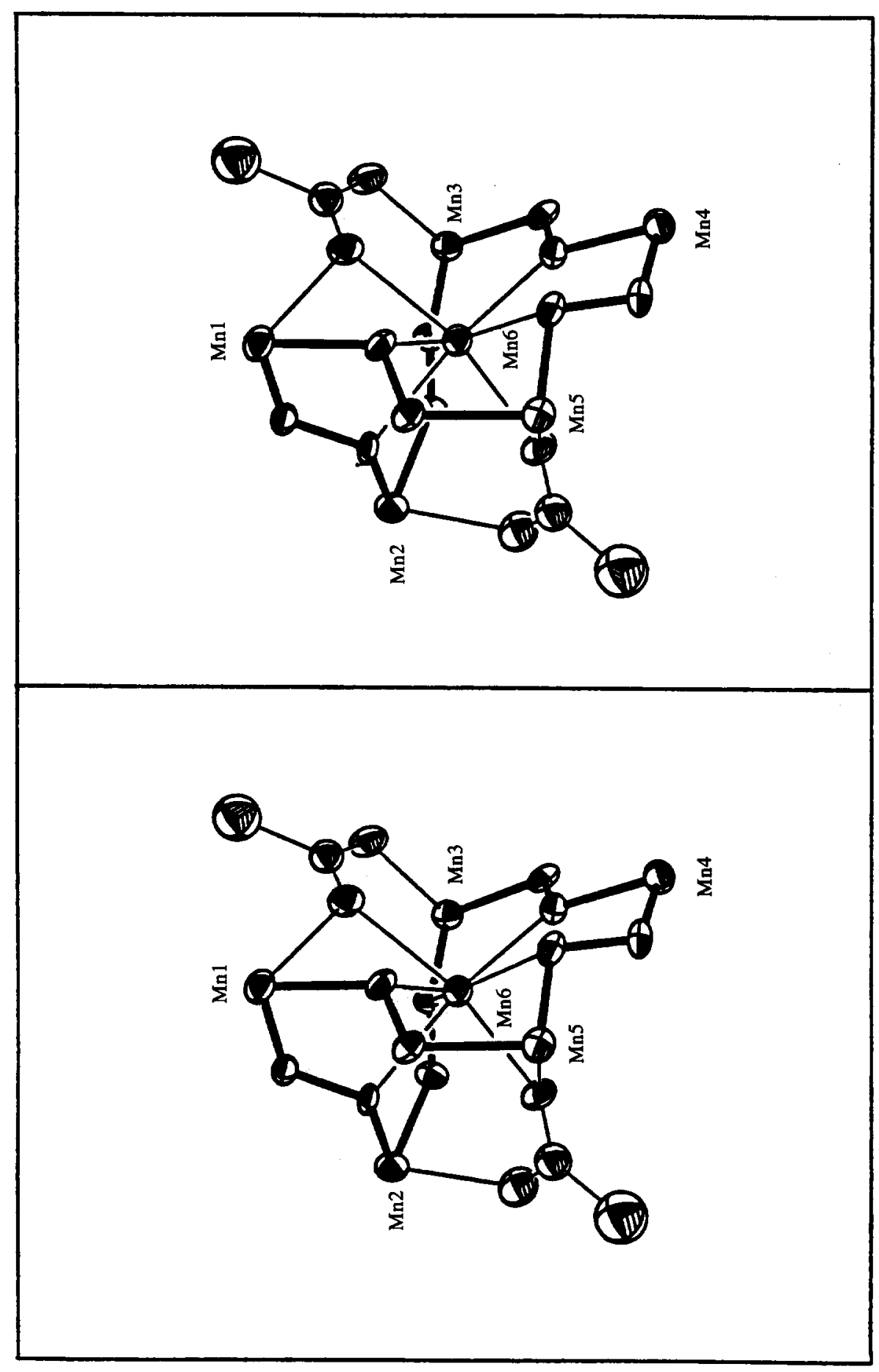

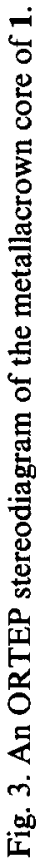



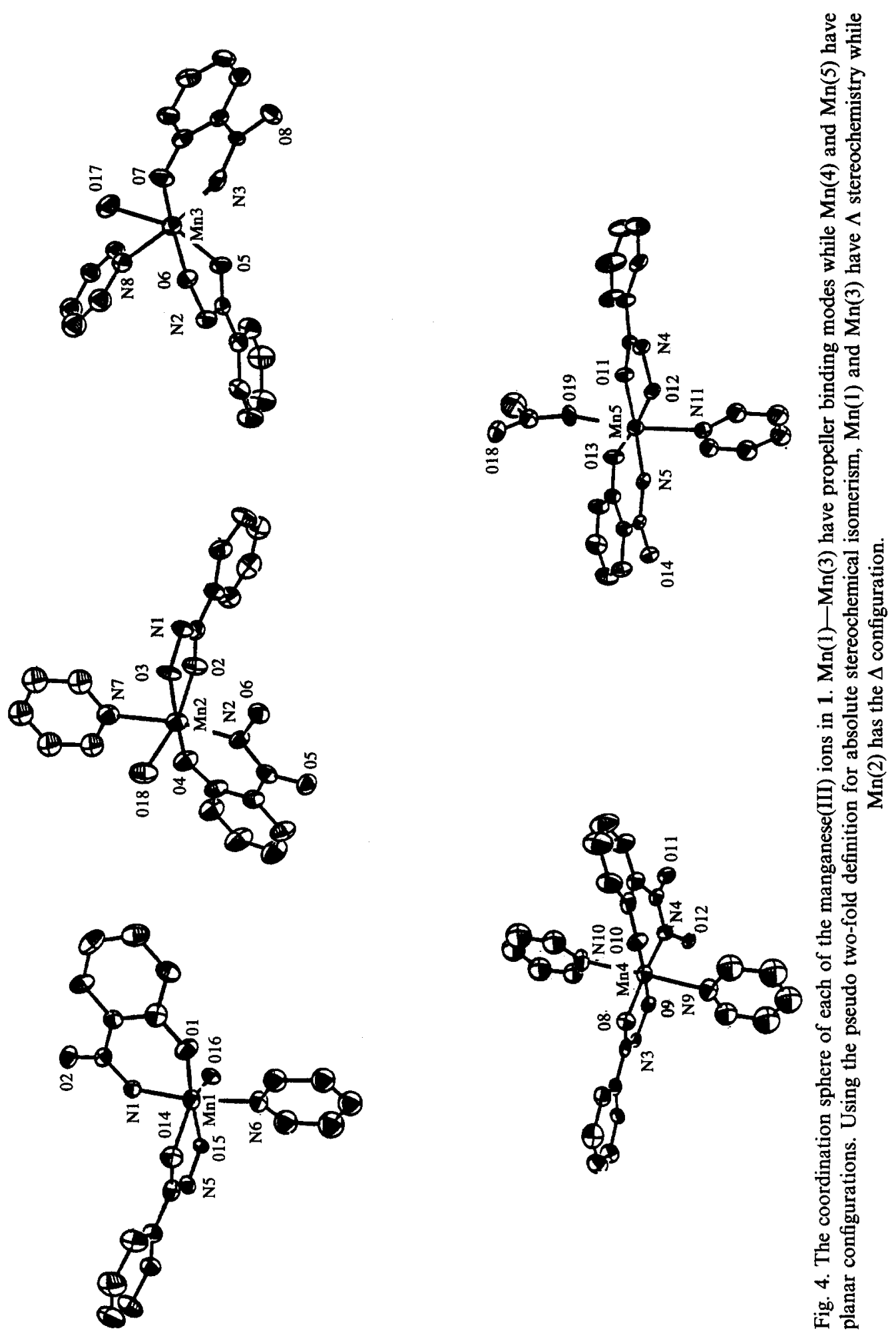


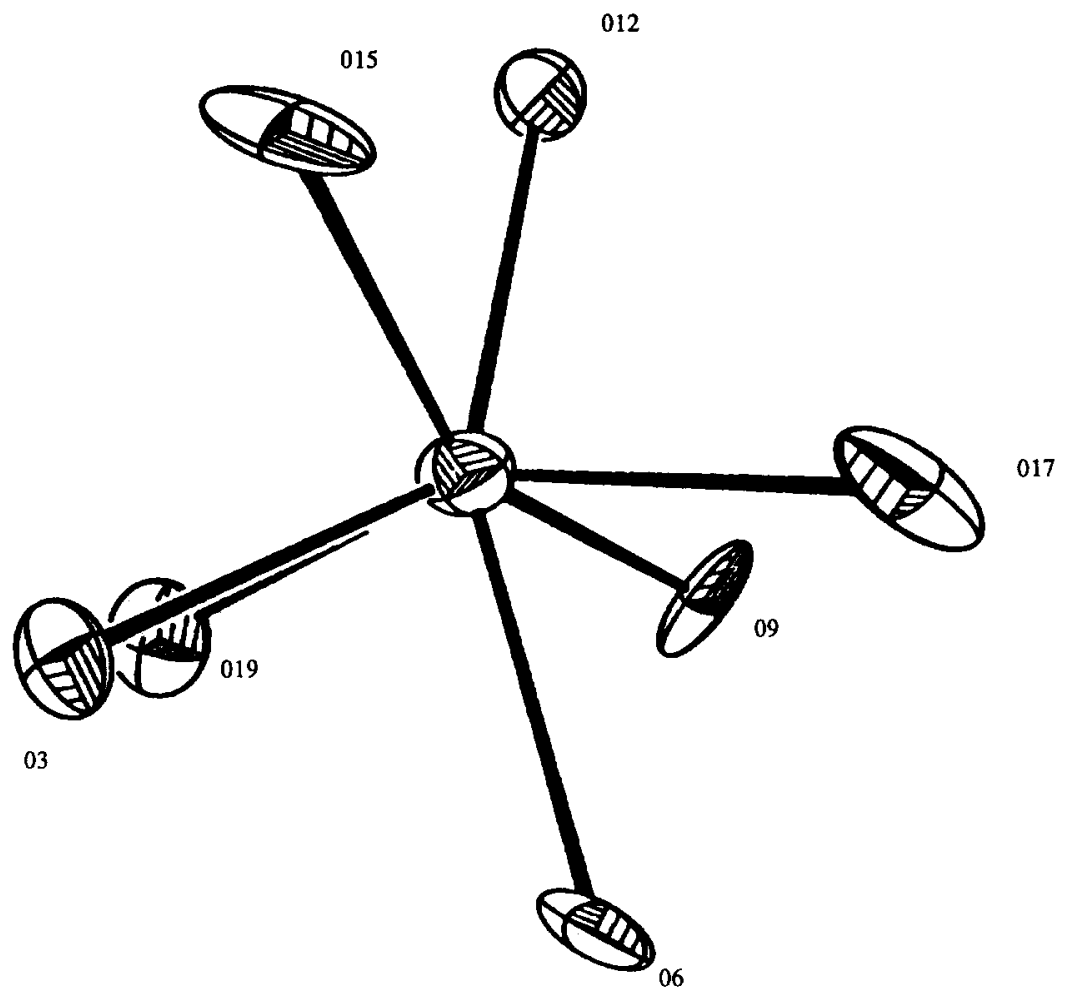

Fig. 5. An ORTEP diagram of the manganese(II) polyhedron [Mn(6)] of 1 .
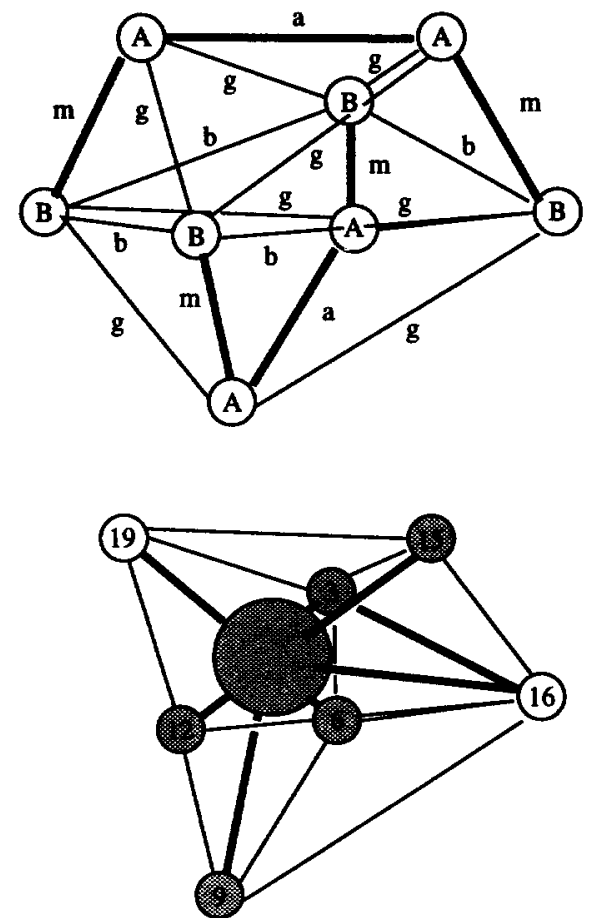

Fig. 6. (Top) An idealized trigonal faced dodecahedron with unique sites and edges labelled. (Bottom) The polyhedron of the manganese(II) ion $[\mathrm{Mn}(6)]$ treated as a dodecahedron with a $\mathbf{B}$ site vacant. Metallacrown ring oxygen atoms $O(3), O(6), O(9), O(12)$ and $O(15)$ are shaded while oxygens from the bridging carboxylates $[O(16)$ and $O(19)]$ are in white. figurations described above imparts flexibility to the ring and expands the cavity size relative to the 12$\mathrm{MC}_{\mathrm{Mn}^{3+} \mathrm{N}^{-}}-4$ complexes (cavity radius for : $1,0.77 \AA$;

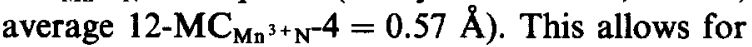
encapsulation of manganese(II) (ionic radius 0.83 $\AA$ ) which is displaced $0.1 \AA$ from the centre of the cavity toward $O(16)$. Acetates provide additional complex stability by forming syn-syn bridges ${ }^{23}$ between $M n(2)$ and $M n(6)$ and $M n(3)$ and $M n(6)$. The two acetates are bound on opposite faces (anti configuration $)^{23}$ of the $15-\mathrm{MC}-5$. The oxygen atoms $[O(16)$ and $O(19)]$ that are bound to $M n(6)$ are bifurcated since they also form weak bonds to $\mathrm{Mn}(1)$ and $\mathrm{Mn}(5) \quad[\mathrm{Mn}(1)-\mathrm{O}(16), 2.372$ $\AA ; \mathrm{Mn}(5)-\mathrm{O}(19), 2.555 \AA]$, respectively. The ring $\mathrm{Mn}(\mathrm{III})-\mathrm{Mn}(\mathrm{III})$ separations are nearly identical to all previous metallacrowns ${ }^{10}$ (average 1 : $4.64 \AA$; average $9-\mathrm{MC}_{\mathrm{Mn}^{3+} \mathrm{N}^{-3}}=4.76 \AA ; 12$ $\mathrm{MC}_{\mathrm{Mn}^{3+} \mathrm{N}}-4=4.71 \AA$ ). The manganese(II) to ring manganese(III) separations are on average $3.49 \AA$ as compared to the average manganese(II) to ring manganese(III) separations of $12-\mathrm{MC}_{\mathrm{Mn}^{3+} \mathrm{N}^{-4}}$ which were $3.54 \AA$.

\section{DISCUSSION}

As described in Scheme 3, [Mn(acetate $)_{2}$ $\left[\mathrm{Mn}(\mathrm{III})(\text { salicylhydroximate }]_{4}(\mathrm{DMF})_{6}\right]$ (3) can be converted to 1 in $\approx 50 \%$ yield by the slow 


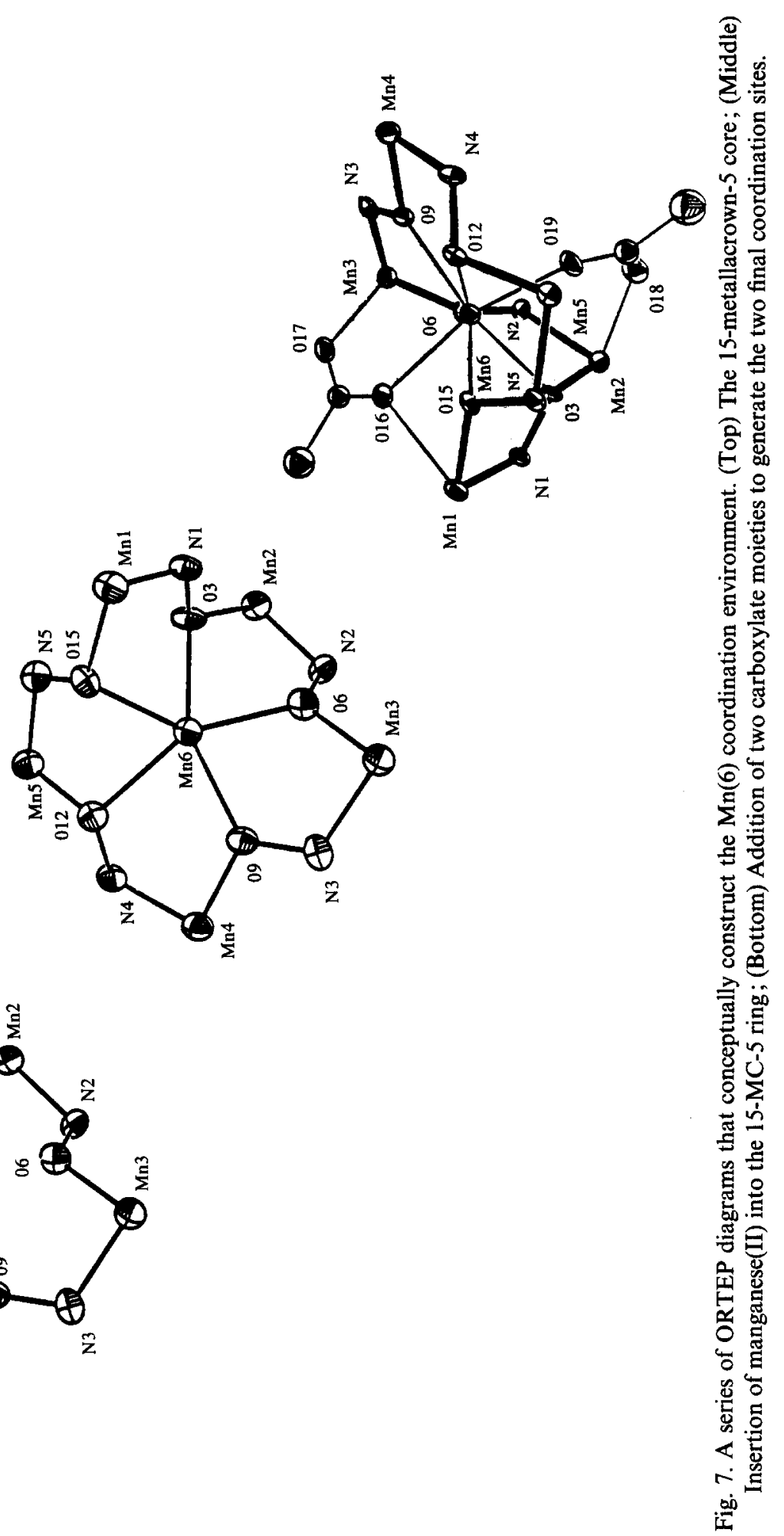




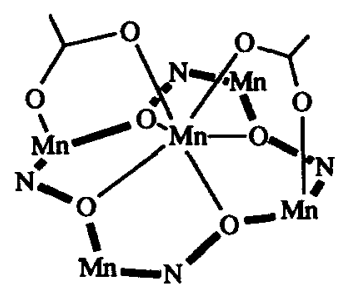

$\mathrm{Mn}(\mathrm{OAc})_{2}\left(12-\mathrm{MC}_{\mathrm{Mn}^{3+} \mathrm{N}^{-4}}\right.$

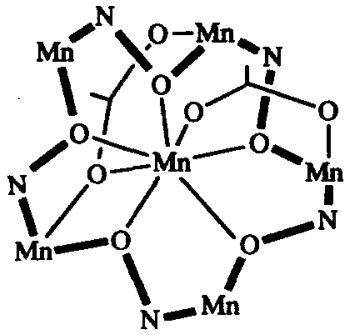

$\mathrm{Mn}(\mathrm{OAc})_{2}\left(15-\mathrm{MC}_{\mathrm{Mn}^{3+} \mathrm{N}^{-5}}\right)$

Scheme 3.

evaporation ( 1 day) of a methanol solution containing a small amount of pyridine ( $5 \%$ by volume). Two related 15-metallacrown-5 complexes can be isolated using this general procedure. Compound 2 , a structural isomer of 1 , is isolated as a crystalline solid $(\approx 20 \%$ yield) when the solution that originally gave 1 is allowed to slowly evaporate for an additional 3 days. Figure 8 illustrates the differences
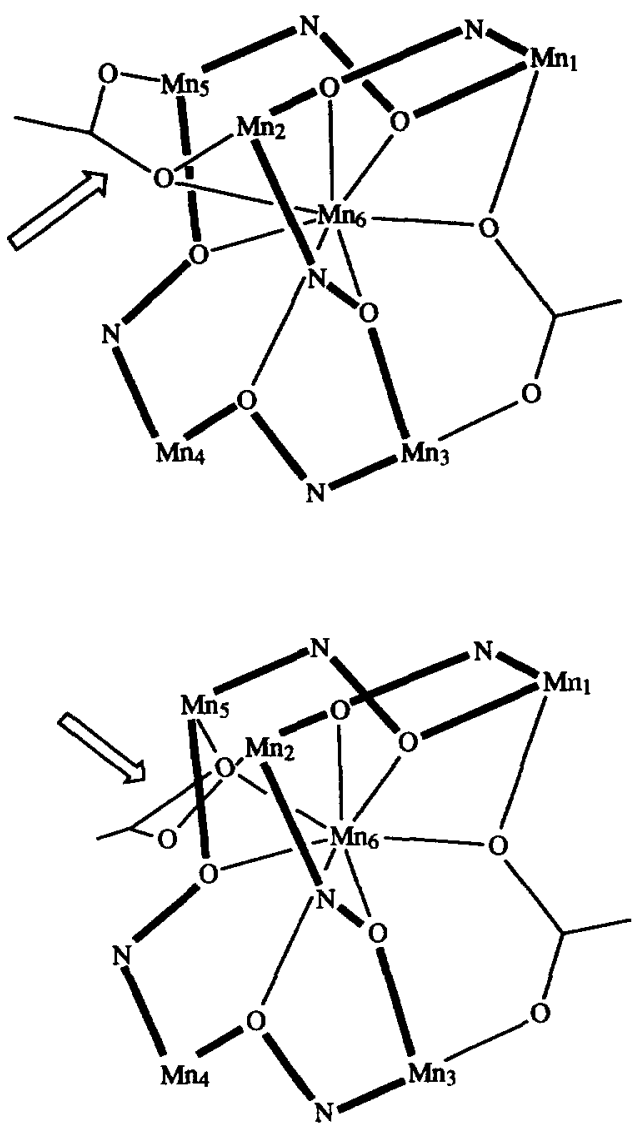

Fig. 8. The two structural isomers of $\mathrm{Mn}(\mathrm{OAc})_{2}$ [15-MC5]. The $\mathrm{G}$ form (up) has a bifurcated carboxylate oxygen between $\mathrm{Mn}(2)$ and $\mathrm{Mn}(6)$ and the $\mathrm{J}$ form (down) has a bifurcated carboxylate oxygen between $\mathrm{Mn}(5)$ and $\operatorname{Mn}(6)$. in the bridging acetate moieties that lead to the structural isomerism. We define these two isomers as $\mathbf{G}$ and $J$ forms. The $G$ form has the bifurcated carboxylate oxygen of the second bridging carboxylate between $\mathrm{Mn}(2)$ and $\mathrm{Mn}(6)$ while the J form has this oxygen between $\mathrm{Mn}(5)$ and $\mathrm{Mn}(6)$.

A third 15-MC-5 structure has been defined as the compositional isomer whereby one of the acetates is displaced by a salicylate carboxylate moiety. Due to the poor crystal quality, we have refrained from providing a detailed structural account of this molecule; however, the core of the molecule is virtually identical to that of 1 . The phenol oxygen of the salicylate molecule is protonated and uncoordinated. Although we did not add salicylate to the crystallization solution, it is not surprising that this molecule can be isolated with this metallacrown since previously we have recovered metal salicylates from metallacrown solutions. ${ }^{10}$ In basic solutions, the salicylhydroxamic acid ligand is susceptible to hydrolysis giving salicylic acid and hydroxylamine. The weak base pyridine, in the presence of water, can promote a small degree of hydrolysis leading to the isolated complex.

\section{Physical properties of 15-MC-5 clusters}

The room temperature solid state magnetic moment is $11.1 \mu_{\text {B.M. }}$. per cluster regardless of isomeric composition (i.e. $\mathbf{G}, \mathbf{J}$ and salicylate metallacrowns). This compares with $13.8 \mu_{\text {B.M. }}{ }^{14}$ and $9.7 \mu_{\text {B.M. }}{ }^{15}$ for $\mathrm{Mn}(\mathrm{OAc})_{2}\left(12-\mathrm{MC}_{\mathrm{Mn}^{3+} \mathrm{N}^{3}}-4\right)$ and $(\mathrm{NaCl})_{2}\left(12-\mathrm{MC}_{\mathrm{Mn}^{3+} \mathrm{N}^{-}}-4\right)$, respectively. A strong sixline epr signal centered at $\mathrm{g}=2$ is observed $(\mathrm{X}$-band frequency, $120 \mathrm{~K}$ ) when 1 is dissolved in methanol suggesting that the captured manganese(II) has dissociated from the complex. A much smaller six-line signal $(\approx 10 \%$ of that in methanol) is seen when an equivalent amount of 1 is dissolved in DMF, whereas there is no epr spectral evidence for free manganese(II) when 1 is dissolved in acetonitrile suggesting that, as was the case for $12-\mathrm{MC}-4$ com- 
plexes, ${ }^{10,14,15}$ the manganese(II) ion is not released from the metallacrown in acetonitrile. Unlike other metallacrowns, 1 is electrochemically inactive in acetonitrile from +2 to $-1.5 \mathrm{~V}$. Thus, the manganese(II) oxidation level is strongly stabilized in the seven-coordinate environment of $\mathrm{Mn}(6)$.

\section{Conversion of 15-MC-5 to 12-MC-4 in DMSO}

The conversion of the $15-\mathrm{MC}-5$ cluster 1 , back to the 12-MC-4 3, cluster can be followed by ${ }^{1} \mathrm{H}$ NMR as shown in Fig. 9. We have previously reported ${ }^{14}$ the ${ }^{1} \mathrm{H}$ NMR of 3 in DMF and acetonitrile. The spectrum in DMSO is also relatively simple with three resonances upfield of the diamagnetic region that are assigned to phenolate protons $(-16.1,-17.7$ and $-26.5 \mathrm{ppm})$. The coordinated acetate resonances are observed at +51.3

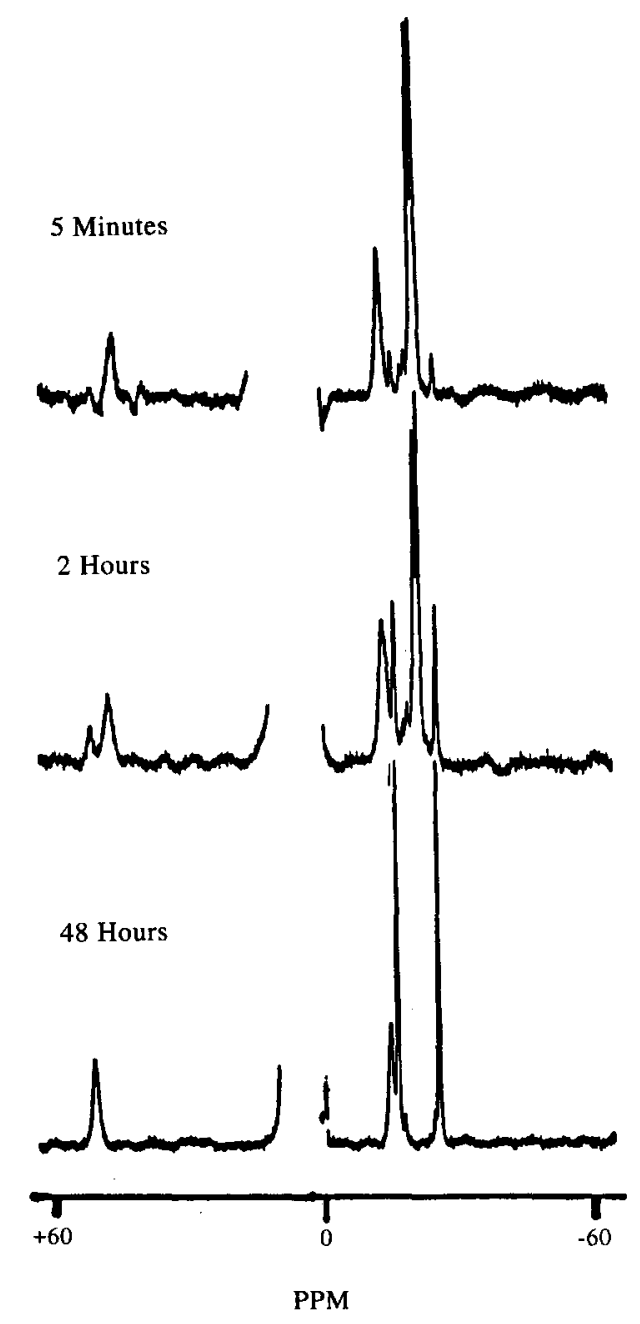

Fig. 9. 'H NMR spectra of 1 dissolved in $\mathrm{d}_{6}$-DMSO. (Top) after $5 \mathrm{~min}$, (middle) after $2 \mathrm{~h}$, (bottom) after $48 \mathrm{~h}$. The bottom spectrum is identical to that of 3 dissolved in $\mathrm{d}_{6}$-DMSO. ppm. The acetate resonances were confirmed by obtaining spectra of 3 prepared using $d_{3}$-acetate.

The ${ }^{1} \mathrm{H}$ NMR spectrum obtained when 1 is dissolved in $d_{6}$-DMSO is shown at the top of Fig. 9. There are three upfield resonances at $-13.8,-21.4$ and $-22.2 \mathrm{ppm}$, assigned to phenolate ring protons by analogy to 3 , and an acetate resonance at +47.2 ppm. New resonances at $-16.1,-17.7,-26.5$ and $+51.3 \mathrm{ppm}$ are observed after $2 \mathrm{~h}$ (middle of Fig. 9) and completely dominate the spectrum after 48 h (bottom of Fig. 9). The new peaks are identical to those obtained when 3 is dissolved in DMSO suggesting that 1 converts slowly to 3 in this donor solvent. This model is supported further by the ultimate, and exclusive, recovery of $\mathbf{3}$ as a solid from this mixture.

We believe the conversion of 1 to 3 is directly related to the substitution of DMSO for pyridine at the ring manganese(III) ions. The coordination chemistry of manganese(III) is dominated by the $d^{4}$ electronic configuration. To remove the degeneracy in the antibonding $e_{g}$ orbitals, manganese(III) either reduces its coordination number to 5 or undergoes a Jahn-Teller distortion (usually an axial elongation). Weak oxygen donors such as DMF or DMSO invariably are located along the Jahn-Teller axis which, for the metallacrowns, requires the ring manganese(III) ions to form the planar configuration. On the other hand, pyridine nitrogens are often found in equatorial positions of the manganese(III) polyhedron as is the case for 1, 2 and 4 . Only through equatorial pyridine ligation can a propeller structure be generated. Thus, as the effective concentration of pyridine is reduced by dissolution into DMSO, the pyridines are displaced and the ring manganese(III) ions convert from propeller to planar conformations. This ultimately requires conversion of the 15-MC-5 to 12-MC-4 structure type. Obviously such a massive reorganization requires a multistep process on going from 1 to 3 ; however, the NMR data do not provide us with enough information to glean the mechanistic details of the 15MC-5 breakdown and 12-MC-4 reassembly.

\section{SUMMARY}

We have presented a new class of hexanuclear mixed valent cluster that has structural similarity to $\mathrm{M}^{2+}\left(15\right.$-crown-5). The $\mathrm{Mn}(\mathrm{OAc})_{2}[15-$ metallacrown-5] expands the ring size of known metallacrown clusters from 9-metallacrown-3 and 12metallacrown-4 to a 15 -membered ring system. A common structural thread is emerging within this structure type. Small ring sizes (9-MC-3) are obtained by having ring metals that can adopt propeller configurations and then templating the sys- 
tem around a small ion that will lead to $\Lambda \Lambda \Lambda$ or $\Delta \Delta \Delta$ ring metal stereochemistry. The intermediate ring size (12-MC-4) is prepared using ring metals that adopt the planar configuration. The large ring system (15-MC-5) is achieved by a mixed propeller/planar ring metal motif in which the propeller metals alternate stereochemistry as $\Lambda \Delta \Lambda$ or $\Delta \Lambda \Delta$ and the planar metals tie two ends together. Based on these observations, we predict that the 18-MC6 heptanuclear cluster should be obtained by templating around a large central metal ion and restricting the ring metals to propeller configurations with alternating $\Lambda / \Delta$ stereochemistry. Furthermore, the vacant site of the trigonal-faced dodecahedral manganese(II) presents an opportunity to bind selectively a small molecule (e.g. $\mathrm{NCS}^{-}$) to the

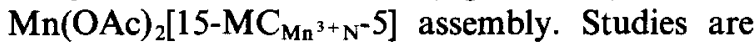
underway to examine these hypotheses.

Acknowledgements-The authors thank Drs Myoung Soo Lah, Dimitri Coucouvanis, Charles Root and Margaret Kastner and $\mathrm{Mr}$ Brian Gibney for useful discussions on this topic. This research was supported by NATO Grant CRG 921338.

Supplementary material-Atomic coordinates and crystallographic data have been deposited with the Cambridge Crystallographic Data Bank.

\section{REFERENCES}

1. C. J. Pederson, J. Am. Chem. Soc. 1987, 89, 2495.

2. C. J. Pedersen, in Synthetic Multidentate Macrocyclic Compounds (Edited by R. M. Izatt and J. J. Christensen), p. 1. Academic Press, New York (1978).

3. B. Dietrich, J. Chem. Ed. 1985, 62, 954; A. V. Bajaj and N. S. Poonia, Coord. Chem. Rev. 1988, 87, 55.

4. R. M. Izatt, J. S. Bradshaw, S. A. Nielson, J. D. Lamb, J. J. Christensen and D. Sen, Chem. Rev. 1985, 85, 271 ; G. A. Melson, Coordination Chemistry of Macrocyclic Complexes. Plenum Press, New York (1979).

5. G. W. Gokel, D. M. Goli, C. Minganti and L. Echegoyen, J. Am. Chem. Soc. 1983, 105, 6786.

6. J.-M. Lehn, Angew. Chem. Int. Ed. Eng. 1988, 27, 89.

7. S. R. Cooper, Acc. Chem. Res. 1988, $21,141$.

8. B. Dietrich, J.-M. Lehn and J. P. Sauvage, Tet. Lett. $1969,2885$.

9. R. Bhula, P. Osvath and D. C. Weatherburn, Coord. Chem. Rev. 1988, 91, 89; M. Micheloni, Comments Inorg. Chem. 1988, 8, 79 and references therein.

10. M. S. Lah and V. L. Pecoraro, Comments Inorg. Chem. 1990, 11, 59.

11. B. Kurzak, E. Farkas, T. Glowiak and H. Kozlowski, J. Chem. Soc., Dalton Trans. 1991, 163.

12. V. L. Pecoraro, Inorg. Chim. Acta 1989, 155, 171.

13. M. S. Lah, M. L. Kirk, W. Hatfield and V. L. Pecoraro, J. Chem. Soc., Chem. Commun. 1989, 1606.

14. M. S. Lah and V. L. Pecoraro, J. Am. Chem. Soc. 1989, 111, 7258 .
15. M. S. Lah and V. L. Pecoraro, Inorg. Chem. 1991, 30, 878 .

16. Our nomenclature is $\mathrm{M}^{\prime} \mathrm{A}\left[\mathrm{X}-\mathrm{MC}_{\mathrm{M}^{\mathrm{n}+} \mathrm{H}^{-}} \mathrm{Y}\right]$ where $\mathrm{X}$ and $Y$ indicate ring size and number of oxygen donor atoms, MC specifies a metallacrown, $M$ and $n$ are the metal and its oxidation state and $\mathrm{H}$ is the identity of the remaining heteroatom bridge. Thus,

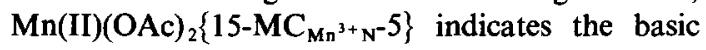
core structure of 15-crown-5 with the carbon atoms replaced by manganese(III) and $\mathrm{N}$ atoms throughout the ring. The manganese(II) is encapsulated by the metallacrown and the two acetates bridge between ring and encapsulated metals.

17. Crystal data for $4: \mathrm{Mn}_{6} \mathrm{C}_{74} \mathrm{H}_{58} \mathrm{~N}_{11} \mathrm{O}_{20}, 7,1751 \mathrm{~g}$ $\mathrm{mol}^{-1}, \quad P \overline{1} ; \quad a=13.932(4) ; b=17.020(8) ; c=$ $18.330(6) \AA ; \alpha=88.93(3)^{\circ} ; \beta=80.84(2)^{\circ} ; \gamma=$ $82.35(3)^{\circ} ; V=4.252(3) \AA^{3} ; Z=2 ; D_{\text {calc }}=11.367(1)$ $\mathrm{g} \mathrm{cm}^{-3} ; \lambda\left(\mathrm{Mo}-K_{\alpha}\right)=0.7107 \AA ; \mu\left(\right.$ Mo- $\left.K_{\alpha}\right)=9.02$ $\mathrm{cm}^{-1}$; crystal dimensions $0.21 \times 0.18 \times 0.13 \mathrm{~mm}$; largest residual $+1.49,0.93 \mathrm{e} / \AA^{3}$. The intensities of 7949 unique reflections were measured between $5<2 \theta<40^{\circ}$ at room temperature on a $P 2_{1} \mathrm{~m} / \mathrm{v}$ diffractometer using $\mathrm{Mo}-K_{\alpha}$ radiation. The structure was solved by direct methods with SHELXTL-PLUS. All manganese atoms of the complex were refined anisotropically while the remaining heteroatoms and carbon atoms of the ligand were refined isotropically. For 4380 data with $\left(F_{\mathrm{o}}\right)>4 \sigma(F)$, the final $R=11.89$.

18. K. D. Bartle, B. J. Dale, D. W. Jones and J. Maricic, J. Mag. Reson. 1973, 12, 286.

19. D. F. Evans, J. Chem. Soc. 1959, 2003.

20. G. M. Sheldrick, SHELEX 1986, SHELEX76, Programs for Crystal Structure Determinations (1976), (1986).

21. International Tables for $X$-ray Crystallography, Vol. 4. Kynoch Press, Birmingham (1974).

22. S. J. Lippard, Progress in Inorg. Chem., Vol. 8, p. 109. John Wiley \& Sons, New York (1967).

23. The syn and anti nomenclature can be confusing in this instance since this terminology can be applied to two different isomer types. When used with respect to bridging carboxylates, the syn/anti nomenclature defines the orientation of the two metals with respect to the carboxylate oxygens. When both metals are in endo positions the bridges are syn, while when metals are bound in exo positions the bridges are anti (e.g. syn bridge; the acetate bridge between $\mathrm{Na}$ and $\mathrm{Mn}$ in $\left[\mathrm{NaMn}_{2}(2-\mathrm{OH}-\mathrm{SALPN})_{2}(\mathrm{OAc})_{4}\right]^{-}$; anti bridge ; $[\mathrm{Mn}(2-\mathrm{OH}-\mathrm{SALPN}) \mathrm{OAc}]_{n}$ both structures are reported in J. A. Bonadies, M. S. Lah, M. L. Kirk, D. P. Kessissoglou, W. H. Hatfield and V. L. Pecoraro, Inorg. Chem. 1989, 28, 2037). In contrast, syn and anti terminology may also describe the spatial relationship of two ligands bound to a molecule with well defined faces. If both ligands are on the same face the complex is syn while ligands on opposing sides are anti (e.g. syn isomer, $\mathrm{Mn}(\mathrm{OAc})_{2}$

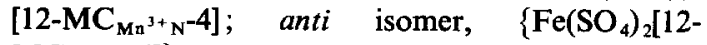
$\left.\mathrm{MC}_{\mathrm{Fe}^{3+} \mathrm{N}^{-4}}\right\}^{-}$reported in reference 10 ). 